\title{
Failure analysis of timber bolted joints by fracture mechanics
}

\author{
L. Daudeville ${ }^{1}$, M. Yasumura ${ }^{2}$ \\ (1) Laboratoire de Mécanique et Technologie, ENS / CNRS / Univ. Paris 6- 61 avenue du Président Wilson, 94230 Cachan Cedex, France, \\ also at IUT de Marne-La-Vallée \\ (2) Building Research Institute, 1-Tatehara, Tsukuba, 305 Japan
}

\section{A B S T R A C T}

This study concerns the failure of dowel-type joints in glued laminated timber under static loading. Failure of joints with a single bolt or dowel due to cracking parallel to the grain direction is considered. Results presented concern only the first mode of cracking, i.e. splitting under tension perpendicular to the grain. Fracture is analyzed by the use of linear elastic fracture mechanics concepts; the crack propagation condition is assumed to be based upon the critical energy release rate $\mathrm{G}_{\mathrm{Ic}}$. A simplified average stress criterion allows predicting the onset of splitting.

An experimental program was carried out on joints for different structural parameters and bolt diameters. The experimental stable crack growth allowed obtaining the load-crack length curves. Another experimental program was carried out in order to compare the fracture energy of a few CIB-type specimens with the critical energy release rate $G_{I_{c}}$ being used in the crack propagation simulation.

The comparison between experimental and numerical results for the simulation of fracture in joints shows that Linear Elastic Fracture Mechanics provides a good approximation of the load-bearing capacity of bolted joints and may help improve design codes.

\section{INTRODUCTION}

Engineering methods for the design of timber mechanical joints are based upon Johansen's yield model [1-5]. This limit analysis method includes connector limit states, but does not take into account the various modes of degradation of wood: cracking parallel to the grain under tearing (mode I) or shearing (modes II and III), failure under tension along the grain direction. Some damage mechanisms are brittle while others are more progressive. Concerning timber, only crushing at

\section{R É S U M É}

Le travail présenté concerne la modélisation et la simulation de la rupture d'un assemblage par tige métallique d'éléments de bois lamellé collé lorsque le phénomène majeur de dégradation est celui de la fissuration parallelement au fil. Nous nous sommes pour l'instant limités à une sollicitation perpendiculaire aux fibres; l'amorçage et la propagation de la fissuration, en mode I dans ce cas, sont étudiés. L'analyse de la propagation d'une fissure est effectuée au moyen de la Mécanique Linéaire Élastique de la Rupture. L'amorşage de la fissuration est prédit par l'utilisation d'un critère simplifié prenant en compte la contrainte moyenne sur une distance supposée caractéristique du matériau.

Les simulations numériques sont comparées à des résultats d'expérimentations pour divers diamètres de tiges et paramètres structuraux. Nous comparons les valeurs simulées et expérimentales des forces d'amorçage de la fissuration ainsi que des forces maximales que l'assemblage peut supporter. Afin de vérifier que la valeur identifiée du taux de restitution d'énergie critique $G_{I c}$ est caractéristique du matériau, une campagne d'essais de fissuration parallèlement au fil du bois par flexion trois points a également été menée sur des éprouvettes de type CIB.

Cette étude montre que la Mécanique Linéaire Élastique de la Rupture peut être appliquée pour la simulation de la rupture d'un assemblage et peut être un outil pour l'amélioration des codes de dimensionnement des assemblages lorsque le phénomène majeur de dégradation du bois est celui de la fissuration parallèlement au fil.

the bolt and wood contact are considered in the Johansen limit analysis.

Normally, bolted joints are designed with the intention of avoiding brittle failure modes associated with catastrophic crack growth parallel to the grain. Nevertheless, the study of that particular failure mode is necessary in order to incorporate into the international codes a reliable method of design of mechanical joints.

Eurocode 5 [2], the proposition for the verification of resistance to a solicitation which is not along the grain direction, consists of the comparison of a mean shear 
stress with a critical value. This criterion may not be convenient because it does not take into account the failure mode and the possible existence of a crack.

The aim of this study is to predict the failure of joints with a single bolt or dowel under a static loading perpendicular to the grain (see Fig. 1). The structural parameters are the bolt diameter $\mathrm{d}$, the end-distance $e_{1}$ and the edge-distance $\mathrm{e}_{2}$.

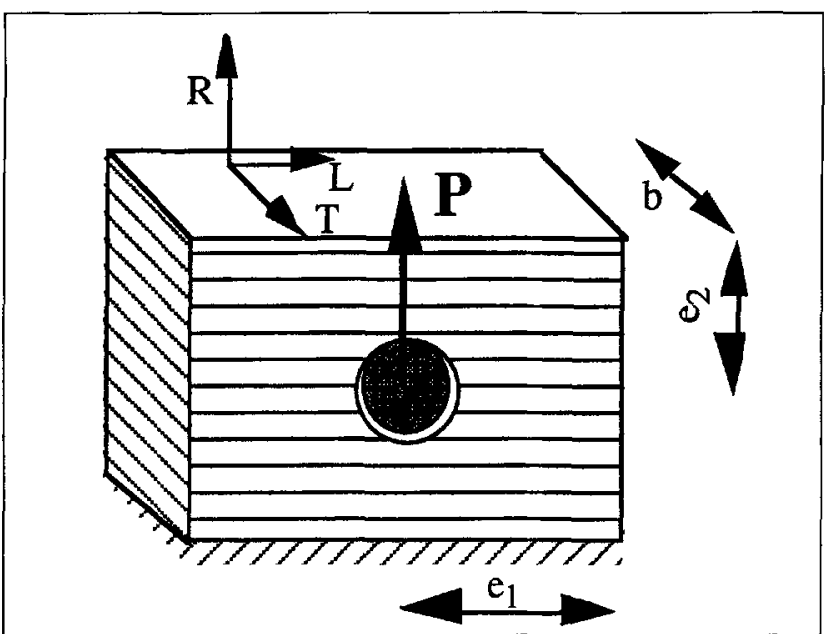

Fig. 1 - Glued-laminated specimen under perpendicular-to-thegrain loading.

In such a case, the failure mode is known. A crack appears at the end of the bolt hole and propagates parallel to the grain ( $\mathrm{L}$ direction) along the weakest plane of wood. This failure mechanism is generally brittle, but the ratio of initiation to ultimate loads can be about $55 \%$ for large values of $e_{1}$ and $e_{2}$. Thus, failure analysis can be applied separately to the study of the initiation of a crack and to that of the propagation of an existing crack.

Numerous experimental studies of mechanical bolted joints have been conducted [6-8]. Rahman et al. [7] combine a finite element analysis with orthotropic criteria to predict initial joint failure when the load is applied parallel to the grain. Previous studies and [8] take into account the non-linear stress-strain behavior of the wood and the friction between the wood and the bolt. These studies are very helpful in investigating the influences of bolt-spacing, enddistance and edge-distance of a multiple fastener when bolt load members are parallel to the grain because, in such a case, the non-linear phenomena have a major influence on stress distribution. The crack propagation was not investigated in previous studies.

For the studied problem, i.e. a loading perpendicular to the grain, wood is assumed to respond linear-elastically to failure. Whitney and Nuismer [9] proposed for composite materials a simplified stress fracture criterion based on the actual stress distribution near a hole or a notch. Following this approach, the initiation of a crack is assumed to occur when the average elastic stress perpendicular to the grain over a characteristic distance from the boundary of the hole equals the tensile strength of the material with no hole. Further investigation is necessary to know if the characteristic distance (or volume) is unique or not for different fracture modes, and if it can be linked to the structure of wood for given species.

Crack propagation is analyzed by the use of classical linear elastic fracture mechanics (LEFM). The application of fracture mechanics to wood has principally concerned the analysis of test specimens for the evaluation of fracture properties [10-12]. For the analysis of mechanical joints, fracture mechanics methods have been scarcely applied. Non-linear phenomena that occur in the socalled process zone of non-linear fracture mechanics have not been considered [13]. In other words, it means that the size of the process zone is neglected in mechanical joints. We combined LEFM with a Griffith criterion based upon the critical energy release rate $\mathrm{G}_{\mathrm{I}}$. The energy release rate was computed with respect to the crack length by the compliance method. Both initiation and propagation were studied with the finite element (FE) code CASTEM 2000.

Failure tests of joints were carried out for different bolt diameters, edge-distances and end-distances. The wood member was composed of glued laminated spruce. The initiation load and the crack length with respect to the load were noted. The only parameter of the model that has been identified with these tests is the critical energy release rate $\mathrm{G}_{\mathrm{Ic}}$. In order to verify the validity of the experimentally-identified critical energy release rate $G_{I_{c}}$, which is characteristic of wood species, a few CIB-type specimens were tested to determine the fracture energy $\mathrm{G}_{\mathrm{If}}$ according to the Draft Standard [10]. Comparisons between experimental and numerical results for studied single-bolted joints with a loading perpendicular to the grain are presented. Initiation and ultimate loads, as well the load with respect to the crack length, are given.

\section{EXPERIMENTAL STUDY OF MECHANICAL JOINTS}

Mechanical joints have been tested at the Laboratory of Mechanics and Technology (LMT) of Cachan [14]. The moisture content and the density of glued laminated members were $10 \%$ and 0.46 respectively. The wood species tested was spruce. The fasteners used were not bolts but steel shafts in order to create a "perfect" contact, i.e. with no allowance between the wood and the shaft.

$\mathrm{d}$ is the shaft diameter, $\mathrm{b}$ is the wood member thickness, $e_{1}$ and $e_{2}$ are the end- and edge-distances respectively, (see Fig. 1). Table 1 presents the different kinds of

\begin{tabular}{|c|c|c|c|c|}
\hline \multicolumn{5}{|c|}{ Table 1- Specimens } \\
\hline Ref. & $\mathrm{d}(\mathrm{mm})$ & $\mathrm{b} / \mathrm{d}$ & $\mathrm{e}_{1} / \mathrm{d}$ & $\mathrm{e}_{2} / \mathrm{d}$ \\
\hline A1 & 12 & 3 & 7 & 4 \\
A2 & 12 & 3 & 7 & 8 \\
A3 & 12 & 3 & 7 & 12 \\
\hline B1 & 16 & 3 & 7 & 4 \\
B2 & 20 & 3 & 7 & 4 \\
\hline C1 & 12 & 3 & 25 & 4 \\
C2 & 12 & 3 & 25 & 8 \\
C3 & 12 & 2 & 25 & 12 \\
\hline
\end{tabular}




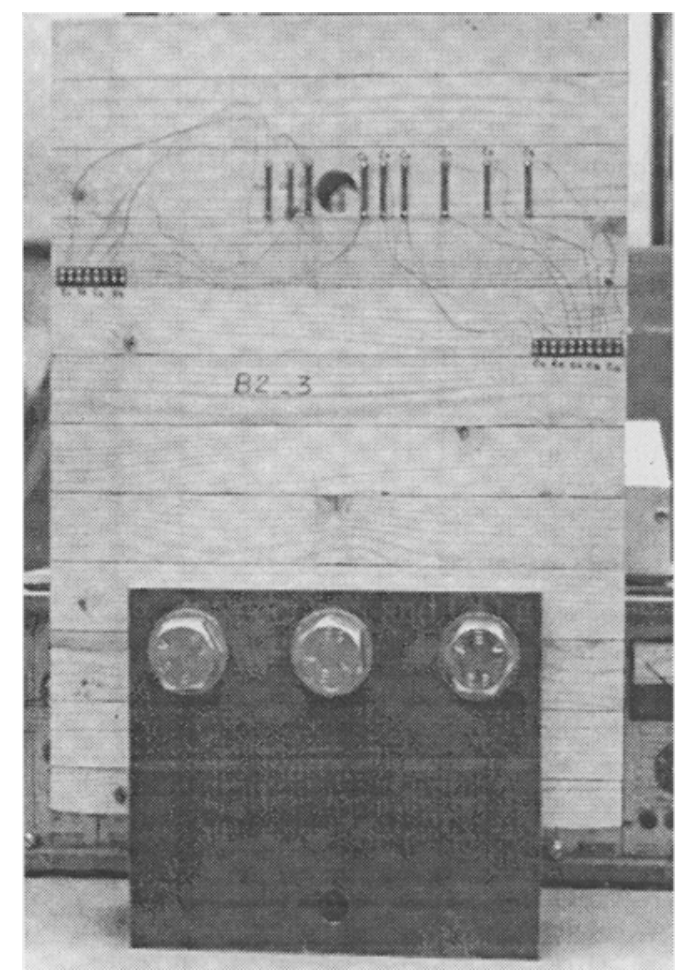

Fig. 2 - Specimen and CD gages.

specimens. For each kind, only a few tests (from 2 to 5 ) have been performed. Contrary to the case of a loading parallel to the grain, the member thickness $b$ does not have a major influence because the bending of the bolt is negligible.

Classical strain gages were used on one face and crack detection (CD) gages on the other (see CD gages on Fig. 2).

Specimens were tested up to failure in stroke displacement control with a head speed of $2.25 \times 10^{-2} \mathrm{~mm} / \mathrm{min}$. This low speed was chosen in order to detect the initiation and to easily follow the stable crack propagation. As opposed to the stroke displacement, the displacement between the steel plates and the wooden member was measured with electronic transducers. Load, strain and displacement were recorded by an $\mathrm{HP}$ workstation at a rate of $1 \mathrm{~Hz}$.

The A1-4 and A1-5 specimens (see Tables 1 and 2) were tested at a speed of $0.18 \mathrm{~mm} / \mathrm{min}$ up to failure in about $300 \mathrm{~s}$, as recommended in Eurocode 5 [2]. We did not notice any important effects on the maximum load of these specimens.

The initiation was detected by considering the three following criteria :

(i) a CD gage near the hole was cut,

(ii) a drop in load was observed,

(iii) a cracking was heard.

Criterion (ii) was suggested by the fact that cracking will decrease the specimen's stiffness. When this decrease results from instantaneous splitting in a joint which is quasi-statically loaded under stroke control, the outcome is an instantaneous drop in load (which may be very small).

Two of the three above criteria had to be verified to consider that initiation had occurred (generally (ii) and (iii)). Table 2 gives the initiation and ultimate loads (the ultimate load is the maximum load).

\begin{tabular}{|c|c|c|}
\hline Specimen & Initiation load & Ultimate load \\
\hline $\begin{array}{l}\text { A1-1 } \\
\text { A1-2 } \\
\text { A1-3 } \\
\text { A1-4 } \\
\text { A1-5 }\end{array}$ & $\begin{array}{l}4.50 \\
4.00 \\
4.70 \\
4.30 \\
4.60\end{array}$ & $\begin{array}{l}4.95 \\
5.03 \\
5.18 \\
4.84 \\
5.22\end{array}$ \\
\hline $\begin{array}{l}\text { A2-1 } \\
\text { A2-2 } \\
\text { A2-3 } \\
\text { A2-4 }\end{array}$ & $\begin{array}{c}4.40 \\
* \\
4.10 \\
* \\
\end{array}$ & $\begin{array}{l}5.10 \\
6.09 \\
4.87 \\
5.22 \\
\end{array}$ \\
\hline $\begin{array}{l}\text { A3-1 } \\
\text { A3-2 } \\
\text { A3-3 }\end{array}$ & $\begin{array}{l}4.30 \\
4.50 \\
4.80\end{array}$ & $\begin{array}{l}4.90 \\
5.44 \\
5.07\end{array}$ \\
\hline $\begin{array}{l}\text { B1-1 } \\
\text { B1-2 } \\
\text { B1-3 }\end{array}$ & $\begin{array}{l}8.00 \\
6.40 \\
7.28\end{array}$ & $\begin{array}{c}10.5 \\
8.49 \\
10.38\end{array}$ \\
\hline $\begin{array}{l}\text { B2-1 } \\
\text { B2-2 } \\
\text { B2-3 } \\
\text { B2-4 }\end{array}$ & $\begin{array}{c}10.00 \\
* \\
9.70 \\
10.50\end{array}$ & $\begin{array}{c}14.7 \\
14.6 \\
11.99 \\
13.8\end{array}$ \\
\hline $\begin{array}{l}\text { C1-1 } \\
\text { C1-2 }\end{array}$ & $\begin{array}{l}5.20 \\
6.10\end{array}$ & $\begin{array}{l}6.27 \\
6.19\end{array}$ \\
\hline $\begin{array}{l}\mathrm{C} 2-1 \\
\mathrm{C} 2-2\end{array}$ & $\begin{array}{c}* \\
4.60\end{array}$ & $\begin{array}{l}7.35 \\
8.72\end{array}$ \\
\hline $\begin{array}{l}\text { C3-1 } \\
\text { C3-2 }\end{array}$ & $\begin{array}{c}4.80 \\
*\end{array}$ & $\begin{array}{l}8.82 \\
10.2\end{array}$ \\
\hline
\end{tabular}

* means an impossibility for the authors to propose an initiation load

Fig. 3 and Fig. 4 are the load-displacement curves for the B2-4 $(\mathrm{d}=20 \mathrm{~mm})$ and $\mathrm{C} 1-1(\mathrm{~d}=12 \mathrm{~mm})$ specimens, respectively. The Fig. 5 curve corresponds to the load with respect to the strain in wood at the bolt and wood contact for the B2-4 specimen. Note an important nonlinearity due to crushing. This non-linearity can also be observed on the load-displacement curves but after initiation, non-linear phenomena seem to be essentially due to splitting (according to visual observation). Also to be noted is the sizable drop in load for the C1-1 specimen (Fig. 4) due to the presence of a knot.

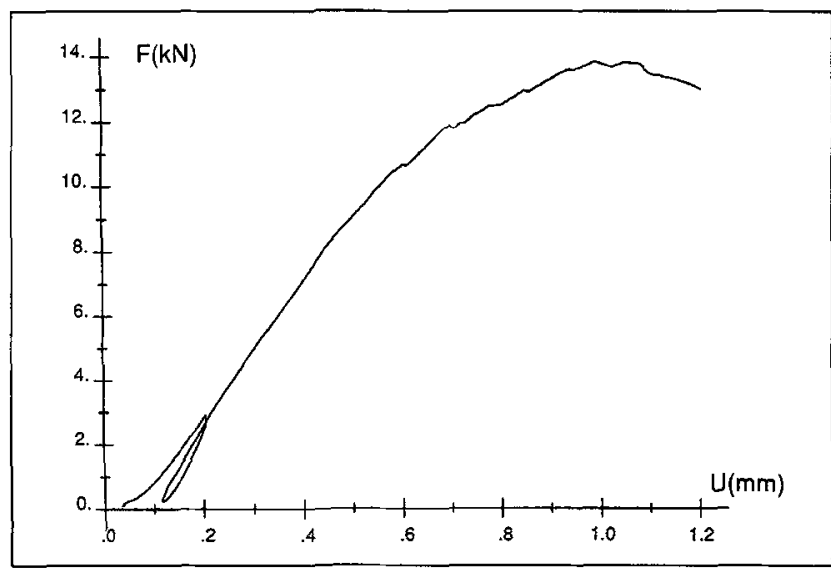

Fig. 3 - B2-4 load-displacement curve (d=20 mm; e1=7d; e2=4d). 


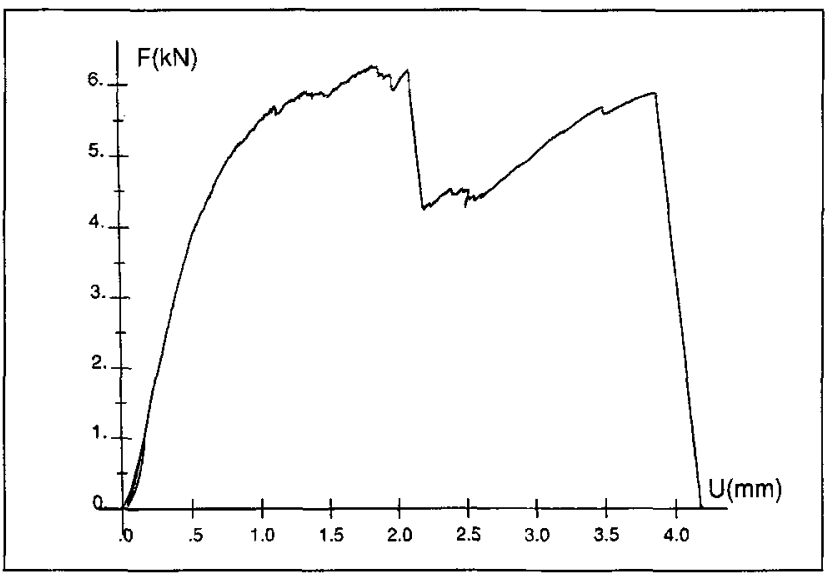

Fig. 4 - C1-1 load-displacement curve $(d=12 \mathrm{~mm} ; \mathrm{e} 1=7 \mathrm{~d} ; \mathrm{e} 2=4 \mathrm{~d})$.

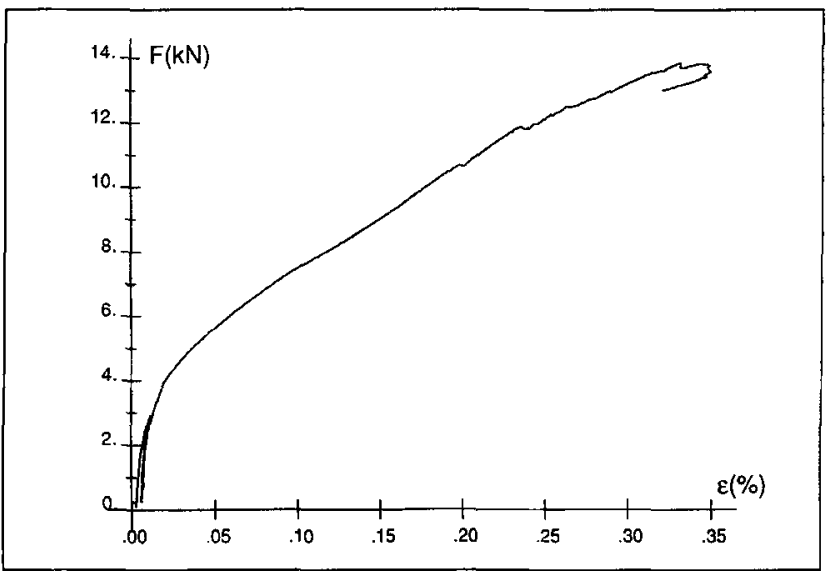

Fig. 5 - B2-4 load-strain curve $(d=20 \mathrm{~mm} ; e 1=7 d ; e 2=4 d)$.

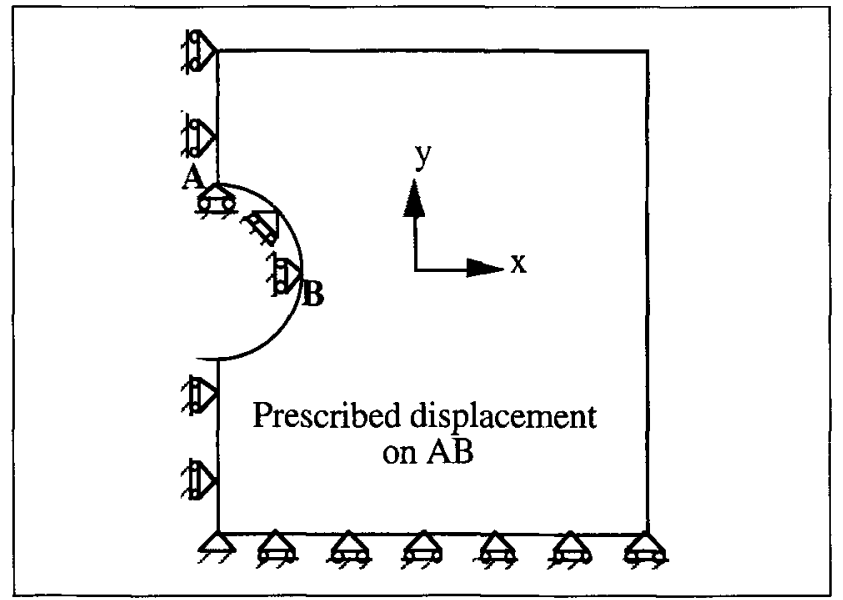

Fig. 6 - Finite element modeling.

\section{MODELING AND SIMULATION}

\subsection{Assumptions}

The modeling assumptions are :

$\mathrm{H} 1$ : Plane stress state,

$\mathrm{H} 2$ : Wood is linear-elastic up to failure,

H3 : The bolt is a rigid body,

H4: The wood and bolt contact is perfect, i.e. with no friction and no allowance,
H5: The transverse $T$ and radial directions $R$ are not distinguished, i.e. the wood is transversally isotropic.

The structure is modeled by finite elements. Because of symmetries, only half of the structure is studied (see Fig. 6).

Assumption $\mathrm{H} 2$ relies on the observation of stressstrain responses that are quasi-linear until failure in tension and non-linear in compression [15].

For a plane problem, the radial $\mathrm{R}$ and transverse $\mathrm{T}$ directions (according to Johnson's notations [16]) cannot be distinguished, so we considered a mean behavior. The elastic moduli were chosen by extrapolation of results [17] with respect to the actual density. The $\mathrm{x}$ direction corresponds to the L direction (Fig. 6).

$$
\begin{aligned}
& E_{x}=15,000 \mathrm{MPa}, \quad E_{y}=\frac{E_{T}+E_{R}}{2}=600 \mathrm{MPa} \\
& G_{x y}=\frac{G_{R L}+G_{T L}}{2}=700 \mathrm{MPa}, \quad v_{x y}=0.5
\end{aligned}
$$

\subsection{Initiation}

The stress state is mainly a tensile one around the point $B$ (see Fig. 6) while a compressive stress state is concentrated at the upper part of the bolt. Degradation takes place in these two regions. The initiation of cracking occurs at the point B (Fig. 6) where a high stress gradient exists. Different fracture criteria for wood exist in the literature [18]. They are expressed in terms of stresses in a coordinate system coinciding with the directions of orthotropy. The failure mode is a pure mode I; these criteria are thus reduced into the comparison of the tearing stress $\sigma_{\mathrm{yy}}$ with the tensile strength $\mathrm{f}_{\mathrm{t}}$ for the cracking onset detection. The mean tensile strength for spruce species (obtained by means of tensile tests performed at CTBA Paris [18]) is:

$$
\mathrm{f}_{\mathrm{t}}=4.76 \mathrm{MPa}
$$

The computation of the local elastic stress $\sigma_{\mathrm{yy}}\left(\mathrm{P}_{\mathrm{c}}\right)$ for the experimental initiation load $\mathrm{P}_{c}$ gives a stress value at point $B$ much higher than $f_{t}$. Note that in the case of a sharp crack, the stress value is infinite. The application of a local approach seems difficult in the case of highstress gradients. In addition, the mesh refinement must be very rich for a good approximation of local elastic stresses in the vicinity of the hole.

Whitney and Nuismer [9] proposed, for composite materials, a simplified stress fracture criterion based on the comparison of the average stress over a characteristic distance $a_{c}$ with the tensile strength $f_{t}$. We applied this approach for the initiation detection. The criterion is (Fig. 7):

$$
\frac{1}{a_{c}} \int_{0}^{a^{c}} \sigma_{y y}\left(P_{c}\right) d x=f_{t}
$$

This "non-local" criterion is less sensitive to the mesh refinement than the local one. 


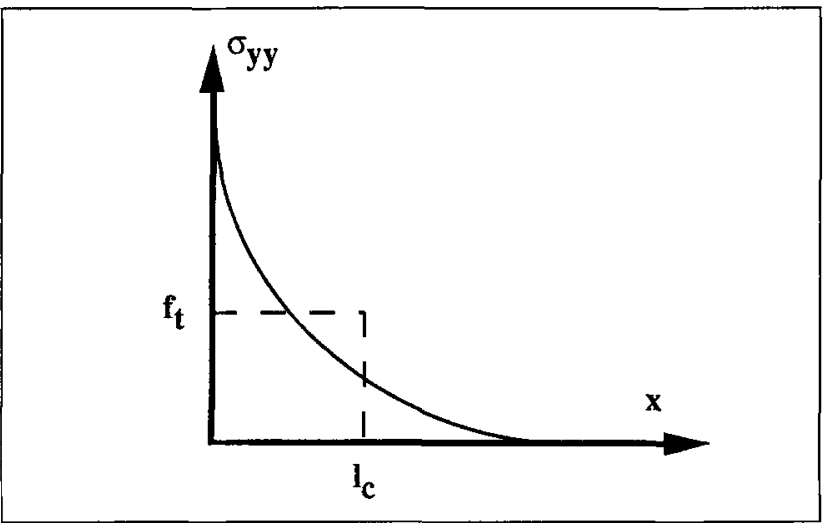

Fig. 7 - Average stress criterion.

Another approach consists of the application of LEFM concepts to the initiation problem by assuming a pre-existing sharp crack. This approach was applied to wood by Sobue [20]. The length of the initial defect is assumed to be intrinsic. The concept of the latter criterion seems similar to that of the average stress criterion, but the computation of the energy release rate or the stress intensity factor is difficult for a very short crack.

In order to identify the distance $a_{i}$, the stress distribution of each specimen denoted $i$ is computed with the experimental initiation load $\left(\mathrm{P}_{\mathrm{c}}\right)_{\text {. }}$. This is an FE computation of the elastic stress distribution. $a_{c}$ is the mean value of the distances $a_{\mathrm{i}}$ for the $n$ specimens.

$$
\mathrm{a}_{\mathrm{c}}=\frac{1}{\mathrm{n}_{\mathrm{i}=1}} \sum_{\mathrm{i}}^{\mathrm{n}} \mathrm{a}_{\mathrm{i}}=2.84 \mathrm{~mm}
$$

The important question is: Is $a_{c}$ an intrinsic material parameter? It is difficult to answer "yes" categorically, but we did not notice any large difference in the $a_{i}$ values for the bolt diameters $\mathrm{d}=12 \mathrm{~mm}, 16 \mathrm{~mm}$ and $20 \mathrm{~mm}$.

The experimental and simulation results concerning the initiation load have been compared (see Figs. 8-9). These figures clearly show, on the one hand, the influence of the bolt diameter and, on the other, the quasi non-influence of the edge-distance on the initiation load with an end-distance equal to $7 \mathrm{~d}$. Table 3 gives the computed initiation load for each specimen to be compared with the experimental one in Table 2.

A further investigation is necessary to know if the characteristic distance (or volume) $a_{\mathfrak{c}}$ is an intrinsic parameter for other geometry and loading.

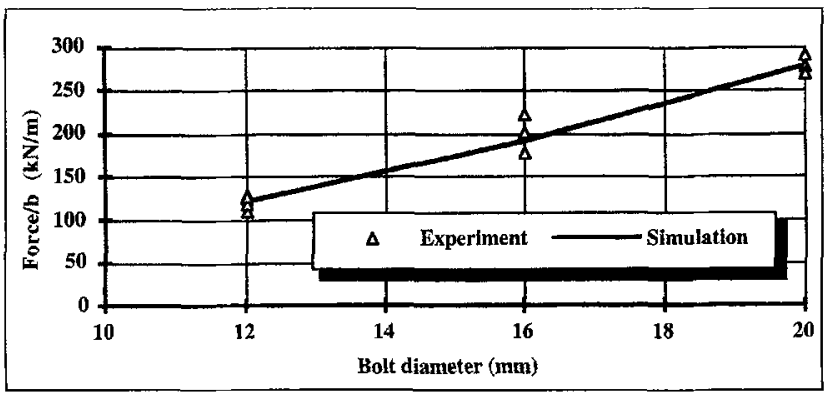

Fig. 8 - Initiation load with respect to the bolt diameter $\left(e_{1}=7 d ; e_{2}=4 d\right)$.

\subsection{Propagation}

The existence of a crack at the point $B$ is now assumed (see Fig. 6). The propagation analysis is carried out by the use of classical LEFM, i.e. all damage phenomena are assumed to occur at the crack tip.

The energy release rate is:

$$
\mathrm{G}=-\frac{1}{\mathrm{~b}} \frac{\partial \mathrm{W}}{\partial \mathrm{A}}=\frac{\mathrm{P}^{2}}{2 \mathrm{~b}} \frac{\partial(1 / \mathrm{k})}{\partial \mathrm{A}}
$$

with W: Potential energy;

A: Crack length;

$\mathrm{k}$ : Mechanical joint stiffness;

b: Specimen width

P: Load.

A Griffith criterion [21] for the crack propagation condition is chosen:

- $\mathrm{G}(\mathrm{P}, \mathrm{A})<\mathrm{G}_{\mathrm{c}} \quad$ No crack propagation

- $\mathrm{G}(\mathrm{P}, \mathrm{A})=\mathrm{G}_{\mathrm{C}}$ Possible crack propagation $\left(\mathrm{P}=\mathrm{P}_{\mathrm{C}}\right)$

and

$\partial G / \partial A(A) \geq 0$ : unstable propagation

$\partial \mathrm{G} / \partial \mathrm{A}(\mathrm{A}) \geq 0$ : stable propagation

$G_{c}=G_{I c}$ is the critical energy release rate for a mode I cracking. The crack is parallel to the grain direction. $\mathrm{G}(\mathrm{A}, \mathrm{P})$ is computed by the compliance method; crack propagation is modeled by separating two connected lines. The mesh refinement at the crack tip is constant during crack propagation.

Thus for FE computations 1 and 2 :

$$
\frac{\mathrm{G}}{\mathrm{P}^{2}}=\frac{1}{2 \mathrm{~b}} \frac{1}{\Delta \mathrm{A}}\left(\frac{1}{\mathrm{k}_{2}}-\frac{1}{\mathrm{k}_{1}}\right)
$$

with $\Delta \mathrm{A}=\mathrm{A}_{2}-\mathrm{A}_{1}$ and $\Delta \mathrm{A} \ll \mathrm{A}$.

The previous relationship allows calculating the force with respect to the crack length for a given critical energy release rate $G_{I c}$ or for a given force to identify $G_{I c}$. Fig. 10 and Fig. 11 represent the computed value $Y=G x(b / P)^{2}$ with respect to the crack length $A / d$ for $e_{1}=7 d, 25 d$ and for different values of the edge-distance $e_{2}$.

For a monotonously-increasing loading and for a Griffith criterion $G=G_{I C}$, the minimum of the curve $\mathrm{Y}(\mathrm{A})=\mathrm{G} \mathbf{x}(\mathrm{b} / \mathrm{P})^{2}$ is the transition point between a stable and an unstable crack propagation (see Figs. 10-11).

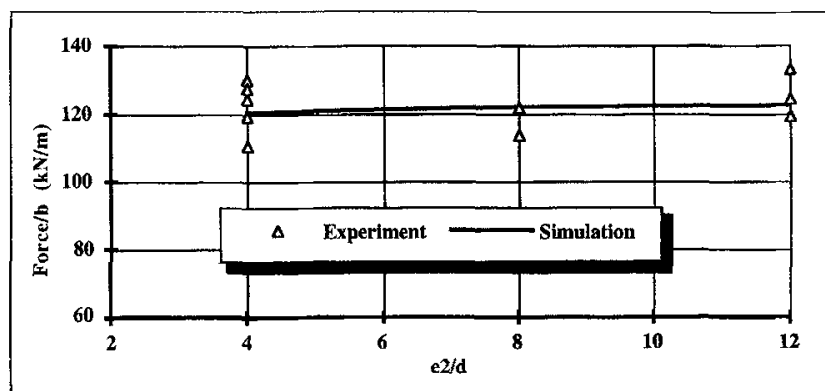

Fig. 9 - Initiation load with respect to the edge-distance $e_{2} / d$ $\left(d=12 \mathrm{~mm} ; \mathrm{e}_{1}=7 \mathrm{~d}\right.$ ). 


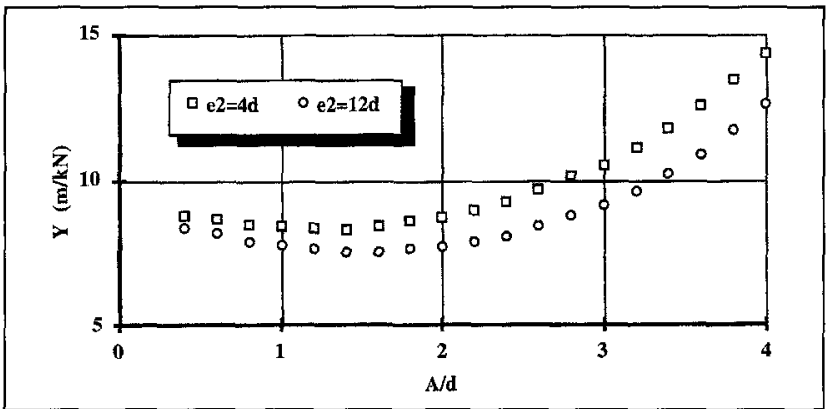

Fig. $10-Y=G \times(b / P)^{2}$ with respect to the crack length $A / d$ $\left(e_{1}=7 d\right)$.

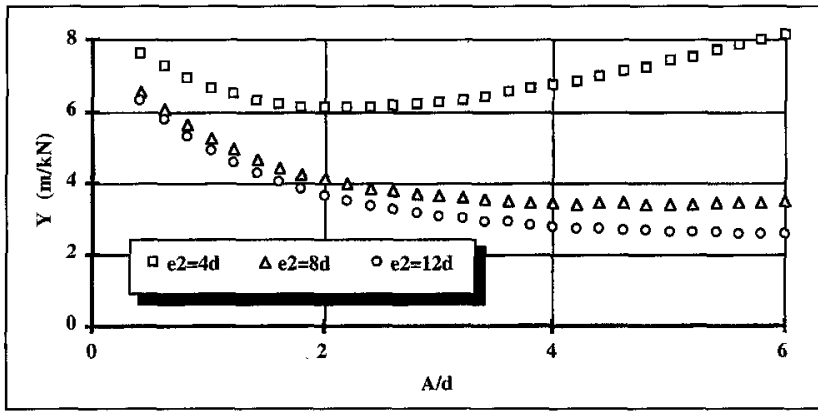

Fig. $11-Y=G \times(b / P)^{2}$ with respect to the crack length $A / d$ $\left(e_{1}=25 d\right)$.

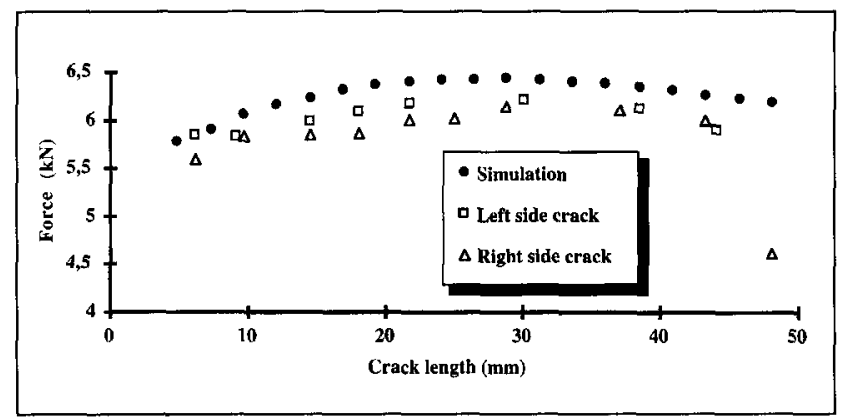

Fig. 12 - Force with respect to the crack length for the C1-1 specimen $\left(d=12 \mathrm{~mm} ; e_{1}=7 d ; e_{2}=4 d\right)$.

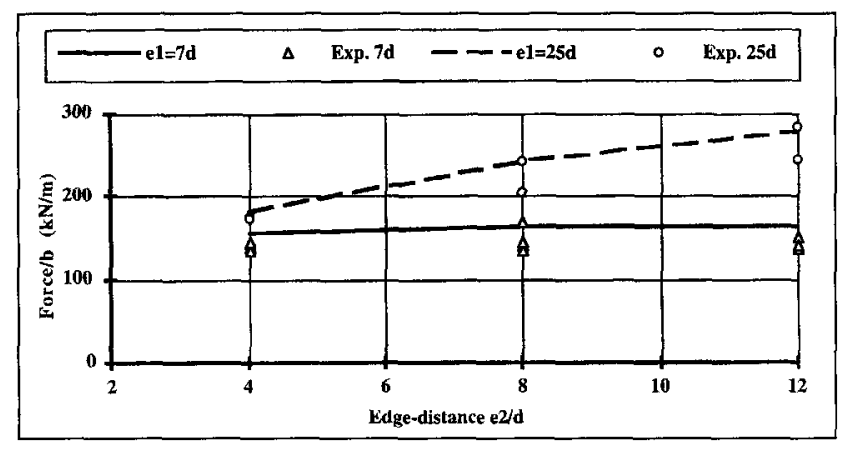

Fig. 13 - Ultimate load with respect to the edge-distance $\left(e_{1}=7 d ; e_{1}=25 d\right)$.

Let us define $A_{c}$ and $P_{c M}$ such that :

$$
\begin{aligned}
& \partial \mathrm{G} / \partial \mathrm{A}\left(\mathrm{A}_{\mathrm{c}}, \mathrm{P}_{\mathrm{cM}}\right)=0 \quad\left(\text { or } \partial \mathrm{Y} / \partial \mathrm{A}\left(\mathrm{A}_{c}, \mathrm{P}_{\mathrm{cM}}\right)=0\right) \\
& \text { and } \mathrm{G}\left(\mathrm{A}_{\mathrm{c}}, \mathrm{P}_{\mathrm{cM}}\right)=\mathrm{G}_{\mathrm{Ic}}
\end{aligned}
$$

The previous loading $\mathrm{P}_{\mathrm{cM}}$ is the maximum loading that the mechanical joint can bear. $A_{c}$ is the critical crack length. The previous curves show that there may be a

\begin{tabular}{|c|c|c|}
\hline \multicolumn{3}{|c|}{$\begin{array}{c}\text { Table 3 - Initiation and ultimate } \\
\text { computed loads }(\mathrm{kN})\end{array}$} \\
\hline Specimen & Initiation load & Ultimate load \\
\hline A1 & 4.34 & 5.58 \\
A2 & 4.40 & 5.86 \\
A3 & 4.41 & 5.87 \\
\hline B1 & 6.85 & 8.6 \\
B2 & 10.05 & 12 \\
\hline C1 & 4.57 & 6.5 \\
C2 & 4.85 & 8.7 \\
C3 & 4.92 & 10 \\
\hline
\end{tabular}

stable crack propagation as the load increases. The critical crack length $A_{c}$ is about one and a half times the bolt diameter with $\mathrm{e}_{1}=7 \mathrm{~d}$ and about six times the bolt diameter with $e_{1}=25 \mathrm{~d}$. These results confirm that the joint does not fail just after the initiation of the crack.

During the controlled stroke displacement test, the ultimate load was reached and the load-displacement curve after the maximum load was also obtained. Table 2 presents the experimental ultimate loads.

It was decided to identify the critical energy release rate $\mathrm{G}_{I \mathrm{I}}$ for that maximum loading. Knowledge of $\left(\mathrm{P}_{\mathrm{cM}}\right)_{\mathrm{i}}$ for each test $\mathrm{i}$ allows computing $\left(\mathrm{G}_{\mathrm{Ic}}\right)_{\mathrm{i}}$.

For instance, let us examine the specimen C1-1 $\left(\mathrm{e}_{1}=25 \mathrm{~d} ; \mathrm{e}_{2}=4 \mathrm{~d} ; \mathrm{d}=12 \mathrm{~mm}\right)$ :

$\left(\mathrm{P}_{\mathrm{cM}}\right) \mathrm{C} 1-1=6.27 \mathrm{kN}$

(Table 2)

$\left(\mathrm{A}_{\mathrm{c}}\right) \mathrm{C} 1=2.4 \mathrm{~d}$ $\left.\begin{array}{l}\left(\mathrm{G}_{\mathrm{Ic}}\left(\mathrm{b} / \mathrm{P}_{\mathrm{cM}}\right)^{2}\right) \mathrm{C} 1=6.11 \mathrm{~m} / \mathrm{kN} \\ (\text { see Fig. 11) }\end{array}\right\} \Rightarrow\left(\mathrm{G}_{\mathrm{Ic}}\right) \mathrm{Cl}-1=186 \mathrm{~N} / \mathrm{m}$

$\mathrm{G}_{\mathrm{Ic}}$ is the mean value of the different $\left(\mathrm{G}_{\mathrm{Ic}}\right)_{\mathrm{i}}$ :

$\mathrm{G}_{\mathrm{IC}}=197 \mathrm{~N} / \mathrm{m}$

The following simulation results were obtained with $\mathrm{G}_{\mathrm{Ic}}=197 \mathrm{~N} / \mathrm{m}$. Fig. 12 shows the comparison between the experimental and computational load-crack length curves for the C1-1 test and for the cracks located on the left and the right parts of the bolt. Table 3 gives the computed ultimate load for each specimen to be compared with the experimental one in Table 2.

Fig. 13 shows the comparison between the computational and experimental ultimate loads for $\mathrm{d}=12 \mathrm{~mm}$. The lines and the points represent the simulations and the tests, respectively. Fig. 14 shows the influence of the bolt diameter.

It was deemed useful to compare the energy release rate with a critical value for the analysis of the propagation of cracking. The same approach was applied with the concept of stress intensity factor. The results are similar. The analysis of a possible multiple cracking (for instance with several bolts) is computationally cheaper by using stress intensity factors because, in such a case, it is necessary to perform an FE computation for each energy release rate corresponding to a possible crack propagation. 


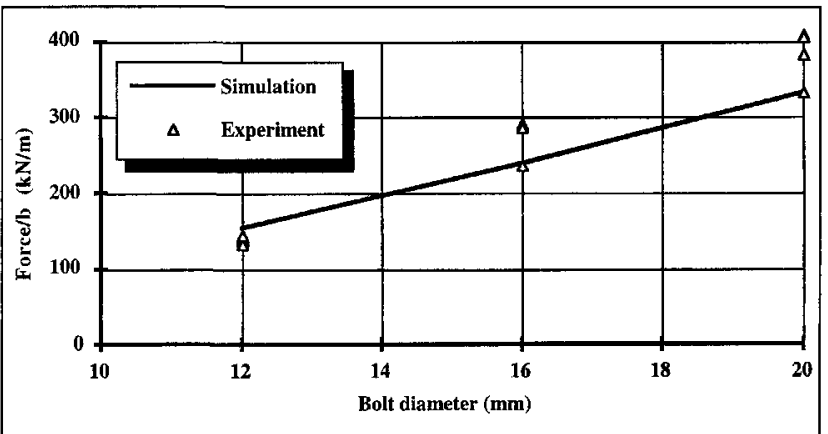

Fig. 14 - Ultimate load with respect to the bolt diameter $\left(e_{1}=7 d ; e_{2}=4 d\right)$.

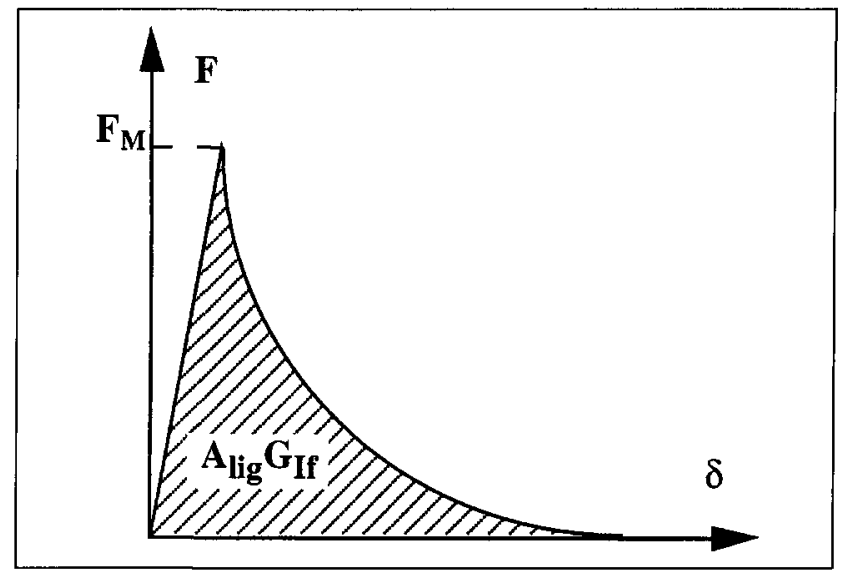

Fig. 15 - Force-displacement curve of a fracture test.

\section{EXPERIMENTAL IDENTIFICATION OF THE FRACTURE ENERGY}

According to LEFM concepts [21], $\mathrm{G}_{\mathrm{Ic}}$ is defined as follows: While a crack starts to grow, the part of the stored elastic energy that is consumed by the fracture process at the crack tip per unit of new separation area is the critical energy release rate $\mathrm{G}_{\mathrm{Ic}}$ (mode I).

Hence, $G_{I c}$ is experimentally identified with the maximum load $F_{M}$ that the specimen can bear during a fracture test (see Fig. 15). A relationship can be established between the critical stress intensity factor $\mathrm{K}_{\mathrm{Ic}}$ and the critical energy release rate $G_{I c}[12]$.

The fracture energy $\mathrm{G}_{\mathrm{If}}$ dissipated during complete crack propagation can also be defined by the integration of the complete load-displacement curve $(\mathrm{F}-\delta)$ of the specimen (see Fig. 15):

$$
\mathrm{G}_{\text {If }}=\frac{1}{\mathrm{~A}_{\text {lig }}} \int_{0}^{\infty} \mathrm{Fd} \delta
$$

$A_{\text {lig }}$ is the area of the uncracked ligament before loading.

If non-linear phenomena due to damage or plasticity are present during crack propagation in a process zone at the crack tip, LEFM is no longer applicable. The consequence is that $\mathrm{G}_{\text {If }}$ and $\mathrm{G}_{\mathrm{Ic}}$ are not equal. In such a case, either non-linear fracture mechanics can be applied [12, 13] or LEFM through using an effective crack length
[22]. $\mathrm{G}_{\mathrm{Ic}}$ is the fracture energy in a linear elastic material with no process zone.

For the studied problem, i.e. the analysis of fracture in a mechanical joint, we assumed that the process zone size is small compared with the crack length and the structure size. Hence, the influence of the process zone is negligible and LEFM can be applied by assuming the fracture energy $\mathrm{G}_{\mathrm{Ic}}$ is equal to $\mathrm{G}_{\mathrm{If}}$.

In order to verify the previous assumption, i.e. to verify the validity of LEFM by using the toughness $\mathrm{G}_{\mathrm{If}}$, a few mode I fracture tests (about 30) were carried out at the Centre Technique du Bois et de l'Ameublement (CTBA Paris). The reference test method chosen was the bending test according to the CIB-Draft Standard [10] (see Fig. 16).

Instead of being computed through tests, $\mathrm{G}_{\text {If }}$ could have been taken from the literature [23] for the wood member species. In such a case, the fracture energy $\mathrm{G}_{\text {If }}$ from [23] is very different from the $G_{I_{C}}$ that was identified with the mechanical joints tests (about $80 \%$ of difference with $\mathrm{G}_{\mathrm{Ic}}=197 \mathrm{~N} / \mathrm{m}$ ).

These experiments consisted of a preliminary test program for the determination of the fracture energy of French spruce; results are given in [24] and [14].

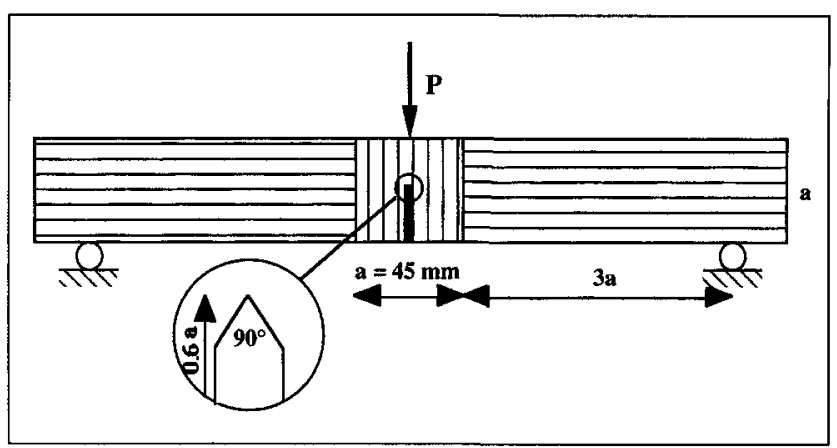

Fig. 16 - Bending test for the determination of the fracture energy in tension perpendicular to the grain.

Specimens were tested under stroke displacement control. The main features of the tests were:

- The head speed was chosen lower than that recommended in [12] in order to have stable cracking,

- The initial defect shape was triangular (see Fig. 16), and

- The initial crack length was $A_{0}=0.6 \mathrm{~h}$ (the specimen section was a square, $h=45 \mathrm{~mm}$ ).

According to the results, the mean experimental fracture energy of spruce in tension perpendicular to the grain and with a density of $460 \mathrm{~kg} / \mathrm{m}^{3}$ is :

$\mathrm{G}_{\mathrm{If}} \approx 180 \mathrm{~N} / \mathrm{m}$

Note that $\mathrm{G}_{\mathrm{If}}$ is not identified with the maximum load $F_{M}$, but with the area of the load displacement curve (see Fig. 15).

This result must be considered with caution because the results showed too much scatter to be able to propose a fracture energy value with so few specimens. Nevertheless, the values of $G_{I c}$ and $G_{\text {If }}$ are close, which could confirm the validity of LEFM for the failure analysis of mechanically bolted joints. 


\section{CONCLUSION}

LEFM is a simplified approach consisting of the comparison of the energy release rate with a critical value. This method has been applied to the determination of the load bearing capacity of a mechanical joint with a single bolt. The fracture mode was the mode I of opening. The critical energy release rate was obtained by testing mechanical joints. This result is in good agreement with the fracture energy value that we obtained with bending fracture tests.

Adjusting this simplified approach for design codes might provide an improvement for the determination of the ultimate load in the design of bolted or nailed joints.

The ultimate load may be much higher than the initiation load of cracking for large values of the end- and edge-distances. The mechanical joint therefore does not fail just after the onset of cracking. The initiation load is also an important piece of data in the design of mechanical joints. The onset of cracking has been predicted by the use of an average stress criterion.

\section{ACKNOWLEDGEMENTS}

The authors would like to thank F. Dubois and A. Bengougam who carried out the experiments in Master's courses at ENS Cachan, and F. Rouger and J.D. Lanvin of the CTBA for providing the specimens and their advice.

\section{REFERENCES}

[1] Johansen, K.W., 'Theory of Timber Connections', Inter. Assoc. of Bridge and Structural Engineering, Bern, Switzerland, Publ. 9 (1949) 249-262

[2] 'EUROCODE 5 - Design of Timber Structure', ENV 1995-1-1, CEN, Brussels (1993).

[3] Yasumura, M., Murota, T. and Sakai, H., 'Ultimate Properties of Bolted Joints in Glued-laminated Timber', CIB-W18A Meeting, paper 20-7-3 (1987).

[4] Yasumura, M., 'Japan Overview: Design concept and prospect of bolted joints and nailed joints', Proceedings of International Workshop on Wood Connectors, Ed. Forest Products Society, ISBN 0.935018.56.5, (1993) 114-121.

[5] Canadian Standards Association, 'Engineering Design in Wood (Limit States Design)', National Standard of Canada CAN/CSA086.1-M89.CSA, Rexdale Ont., Canada (1989).
[6] Ehlbeck, J., Gorlacher, R. and Werner, H., 'Determination of Perpendicular-to-grain Tensile Stresses in Joints with Doweltype-fasteners', CIB-W18A Meeting, Berlin Germany, paper 227-2 (1989)

[7] Rahman, M.U., Chiang, Y.J. and Rowlands, R.E., 'Stress and failure analysis of double-bolted joints in Douglas-fir and Sitka spruce", Wood and Fiber Science 23 (4) (1991) 567-589.

[8] Bouchaïr, A., 'Modélisation non Linéaire du Comportement Local des Assemblages Bois', Thèse de l'Université Blaise Pascal, Clermont-Ferrand (1993).

[9] Whitney, J.M. and Nuismer, R.J., Joumal of Composite Materials 8 (1974) 253-265.

[10] Larsen, H.J. and Gustafsson, P.J., 'Design of End-notched Beams', CIB-W18A Meeting, Berlin Germany, paper 22-10-1 (1989).

[11] Valentin, G. and Adjanohoun, G., 'Applicability of classical isotropic fracture mechanics specimens to wood crack propagation studies', Materials and Structures 25 (1992) 3-13.

[12] Valentin, G., Boström, L., Gustafsson, P.J., Ranta-Maunus, A. and Gowda, S., 'Application of Fracture Mechanics to Timber Structures', RILEM State-of-the-art Report, Technical Research Centre of Finland, Espoo Finland, Research Notes 1262, ISBN 951.38.3891.1 (1991).

[13] Boström, L., 'The fictitious crack model - A fracture mechanics approach applied to wood', International Conference on Timber Engineering, Seattle, 2, (1988) 559-565.

[14] Bengougam, A. and Dubois, F., 'Simulation de la Rupture d'un Assemblage en Bois Boulonné, LMT, Mémoire de D.E.A. de l'ENS. de Cachan (1994).

[15] Gautherin, M.T., 'Critère de Contrainte Limite du Bois Massif', LMT, Thèse de l'Université Paris 6 (1980).

[16] Johnson, J.A., 'Crack initiation in wood plates', Wood Sci. 6 (2) (1973) 151-158.

[17] Guitard, D., 'Mécanique du Matériau Bois et Composites', Cépadues-Éditions, ISBN 2.85428.152.7. (1987).

[18] CTBA, 'Étude des Caractéristiques Mécaniques du Sapin et de l'Épicéa - France Entière', Internal report.

[19] Rathkjen, A., 'Failure Criteria for Wood', in 'Failure Criteria of Structured Media', Boehler (ed.) (Balkema, Rotterdam, The Netherlands), ISBN 9.06191.179.6. (1993).

[20] Sobue, N., Scientific Report for the "Grant-in Aid Scientific Research", n 62560174, Ministry of Education, Science and Culture, Japan (1989).

[21] Griffith, A., 'The Phenomena of Rupture and Flow in Solids', Philosophical Transactions of the Royal Society of London, Series A, 221 (1920) 163-198.

[22] Nallathambi, P. and Karihaloo, B.L., 'Notched beam test: Mode I Fracture Toughness', Fracture Mechanics Tests for Concrete, Report of Technical Committee 89-FMT, RILEM, edited by Shah, S.P. and Carpinteri, A. (Chapman and Hall, London, 1991) $1-86$

[23] Larsen, H.J. and Gustafsson, P.J., 'The Fracture Energy of Wood in Tension Perpendicular to the Grain', CIB-W18A Meeting, Lisbon Portugal, paper 23-19-2 (1990).

[24] Daudeville, L., Yasumura, M. and Lanvin, J.D., 'Fracture of Wood in Tension Perpendicular to the Grain: Numerical Simulation by Damage Mechanics', CIB-W18A Meeting, Copenhagen, Denmark, paper 28-19-1 (1995). 